\title{
ОЦЕНКА ОБРАЗЦОВ ЯРОВОЙ МЯГКОЙ ПШЕНИЦЫ СИБИРСКОЙ СЕЛЕКЦИИ ПО АДАПТИВНОСТИ В УСЛОВИЯХ КРАСНОЯРСКОЙ ЛЕСОСТЕПИ
}

\author{
V.I. Nikitina, D.F. Fedosenko
}

\section{THE ASSESSMENT OF SPRING SOFT WHEAT SAMPLES OF SIBERIAN SELECTION BY ADAPTABILITY IN THE CONDITIONS OF KRASNOYARSK FOREST STEPPE}

Никитина Вера Ивановна - д-р биол. наук, проф. каф. ландшафртной архитектуры и ботаники Красноярского государственного аграрного университета, г. Красноярск.

E-mail: vi-nikitina@mail.ru

Федосенко Денис Федорович - асп. каф. ландшафтной архитектуры и ботаники Красноярского государственного аграрного университета, г. Красноярск. E-mail: day-black@mail.ru

Цель исследований: изучить адаптивные свойства 33 образцов яровой мягкой пшеницы сибирской селекции как исходный материал для создания сортов с высокой устойчивостью к неблагоприятным условиям. Полевые исследования проведены на опытном поле в ОПХ «Минино» Красноярского НИИСХ в 20172019 г2. Выявлено в условиях Красноярской лесостепи высокое влияние сорта (47,8 \%) и условий вегетации (38,0 \%) на изменчивость урожайности изучаемых образцов пшеницы. Роль взаимодействия этих двух фракторов значительно меньше - 8,9 \%. Более низкую урожайность имели раннеспелье и среднеранние образцы пшеницы: Новосибирская 14, Новосибирская 15, Новосибирская 31, Чулымская, Канская, Зоряна, Руслада, Скала, Памяти Вавенкова. Достоверно превышали их по урожайности среднеранние сорта: Тулунская 12, Новосибирская 29, Уярочка, Омская 32. У среднеспелой группы существенно выделились по отношению к стандарту (Алтайская 75) 8 образцов: Предгорная, Красноярская 12, К-543-2, К-527-2, К-518-4, Омская Краса, Новосибирская 18, К-524-2. Высокие показатели относительной стабильности урожайности во времени получены у образцов селекции Красноярского НИИСХ: Красноярская 12, Уярочка, К-518-4, Чу-
Nikitina Vera Ivanovna - Dr. Biol. Sci., Prof., Chair of Landscape Architecture, Botany, Agroecology, Krasnoyarsk State Agrarian University, Krasnoyarsk. E-mail: veranikitina@rambler.ru

Fedosenko Denis Fedorovich - Post-Graduate Student, Chair of Landscape Architecture, Botany, Agroecology, Krasnoyarsk State Agrarian University, Krasnoyarsk. E-mail: day-black@mail.ru

лымская, К-543-2, К-613-2 и Руслада (Кемеровская обл.). Определение показателя относительной стабильности и средней стабильной урожайности позволил дифрференцировать образцы яровой мягкой пшеницы по их реакции на условия воздельвания. Изученные образцы рекомендуются как исходный материал для селекции разных типов сортов с высокой устойчивостью $к$ неблагоприятным условиям вегетации, адаптированных на изменение уровня агротехники.

Ключевые слова: яровая пшеница, адаптивность, изменчивость, урожайность, селекция, показатель относительной стабильности признака, средняя стабильная урожайHOCMb.

The aim of the research is to study adaptive properties in 33 samples of spring soft wheat of Siberian selection as the source material for the varieties creation with high resistance to adverse conditions. Field studies were conducted on experimental field "Minino" of Krasnoyarsk Research Institute of Agriculture in 2017-2019. High influence of the variety $(47.8 \%)$ and growing conditions (38.0\%) on variability in the yields of studied wheat samples was detected in the conditions of the Krasnoyarsk forest steppe. The role of interaction between these 
two factors was much less - $8.9 \%$. Lower yields had early and mid-early wheat samples were Novosibirskaya 14, Novosibirskaya 15, Novosibirskaya 31, Chulymskaya, Kanskaya, Zoryana, Ruslada, Scala, Pamyati Vavenkova. Mid-early varieties Tulunskaya 12, Novosibirskaya 29, Uyarochka, Omskaya 32 reliably exceeded their yields. In mid-season group 8 samples were significantly distinguished in relation to the standard (Altayskaya 75): Predgornaya, Krasnoyarskaya 12, K-543-2, K-527-2, K-518-4, Omskaya Krasa, Novosibirskaya 18, K-524-2. High indicators of relative stability of yield over time were obtained from the samples of Krasnoyarsk Research Institute of Agriculture selection: Krasnoyarskaya 12, Uyarochka, K-518-4, Chulymskaya, K-543-2, K613-2 and Ruslada (Kemerovo Region). The definition of the indicator of relative stability and stable average yields allowed to differentiate the samples of spring soft wheat for their reaction to cultivation conditions. The studied samples were recommended as a source material for the selection of different types of varieties with high resistance to unfavorable vegetation conditions, adapted for changing level of agrotechnology.

Keywords: spring wheat, adaptability, variability, productivity, selection, indicator of relative sign stability, average stable yield.

Введение. В настоящее время селекционный процесс в России направлен на создание сортов, обладающих повышенной пластичностью, устойчивостью к болезням и вредителям, дающих высокую стабильную урожайность, максимально использующих климатический потенциал зоны возделывания [1-9]. Сорта должны быть хорошо приспособлены к колебаниям погодных условий в течение вегетационного периода, к пониженной влагообеспеченности, быстро расти и развиваться, реагировать на улучшение условий выращивания в каждой конкретной экологической зоне.

Повышение урожайности в развитых странах на 90-95 \% зависит от генетико-селекционного создания сортов и гибридов и только на 5-10 \% от совершенствования агротехнологий [10]. Многие современные сорта и гибриды недостаточно приспособлены для конструирования высокоурожайных, экологически устойчивых агроэкосистем и агроландшафртов.
А.А. Жученко отмечает, что в сельскохозяйственном производстве у сортов реализуется около 30-40 \%, а в лучшем случае - 50-60 \% потенциальной их продуктивности, основной причиной этого является их недостаточная экологическая устойчивость [11].

Важной проблемой экологической селекции является теоретическое обоснование создания специализированных сортов со специфической адаптивностью для каждой почвенноклиматической зоны [2].

Современное растениеводство Красноярского края, учитывая его природно-климатические особенности, ограниченность использования минеральных удобрений и других средств химизации при возделывании зерновых культур, нуждается в адаптированных к условиям среды сортах. Для создания таких сортов, приспособленных к узкой экологической нише, необходим подбор исходного материала. Прообразом его являются местные сорта, представляющие уникальный набор коадаптированных блоков генов, обеспечивающих максимальное использование условий внешней среды [11].

Оценка стабильности и пластичности сортов яровой пшеницы позволит установить достоверность наблюдаемых различий по урожайности и получить необходимую информацию для отбора ценного исходного материала при селекции на адаптивность.

Цель исследований: оценка экологической пластичности и стабильности образцов яровой мягкой пшеницы сибирской селекции в условиях Красноярской лесостепи по количественному признаку «урожайность зерна».

Исходный материал и методика исследований. Для оценки адаптивного потенциала в ОПХ «Минино» Красноярского НИИСХ ФИЦ КНЦ СО РАН в 2017-2019 гг. были проведены полевые исследования 33 образцов сибирской селекции. Стандартные сорта по группам спелости: раннеспелые, среднеранние - Алтайская 70; среднеспелые - Алтайская 75; среднепоздние - Свирель. Посев проводили по чистому пару в оптимальные для Красноярской лесостепи сроки (17-20 мая), сеялкой ССФК-7, в четырехкратной повторности с нормой высева 500 всхожих зерен на $1 \mathrm{~m}^{2}$. Площадь делянок $3,26 \mathrm{~m}^{2}$, учетная - $3 \mathrm{~m}^{2}$. 
Постановку опытов, учеты и наблюдения осуществляли в соответствии с методикой государственного сортоиспытания сельскохозяйственных культур и методическими указаниями ВНИИР по изучению мировой коллекции пшеницы [12-14].

Определение средней стабильной урожайности, показателя относительной стабильности признака рассчитывали по Н.А. Соболеву [15].

Результаты исследований. Метеорологические условия в годы исследований (20172019 гг.) отличались друг от друга и от средней многолетней нормы. Характерной особенностью этих лет являлось наличие весенне-летней засухи, которая особенно была выражена в 2019 г. Недостаточное количество осадков выпало в июле (0-98,7 \%), меньше всего в 2018 г.: от 0 \% (II декада) до 50,7 \% (І декада) от нормы.
По среднесуточной температуре воздуха периоды вегетации растений были различны, наиболее отчетливо - во второй декаде мая, первой декаде июня и июля, третьей декаде июля и все декады августа. В годы опытов выше климатической нормы среднесуточные температуры воздуха имели место в третьей декаде мая (на $\left.1-4,7^{\circ} \mathrm{C}\right)$, второй $\left(0,3-2,3^{\circ} \mathrm{C}\right)$ и третьей $(1,6-$ $\left.5,4{ }^{\circ} \mathrm{C}\right)$ декадах июня, ниже средних многолетних данных - во второй декаде июля (на 0,2$2,0^{\circ} \mathrm{C}$ ). Разнообразие и контрастность погодных условий в течение вегетации способствовали объективной оценке исходного материала.

Исследования в условиях Красноярской лесостепи позволили выявить высокое влияние сорта $(47,8 \%)$ и условий вегетации $(38,0 \%)$ на изменчивость урожайности яровой пшеницы (рис.).

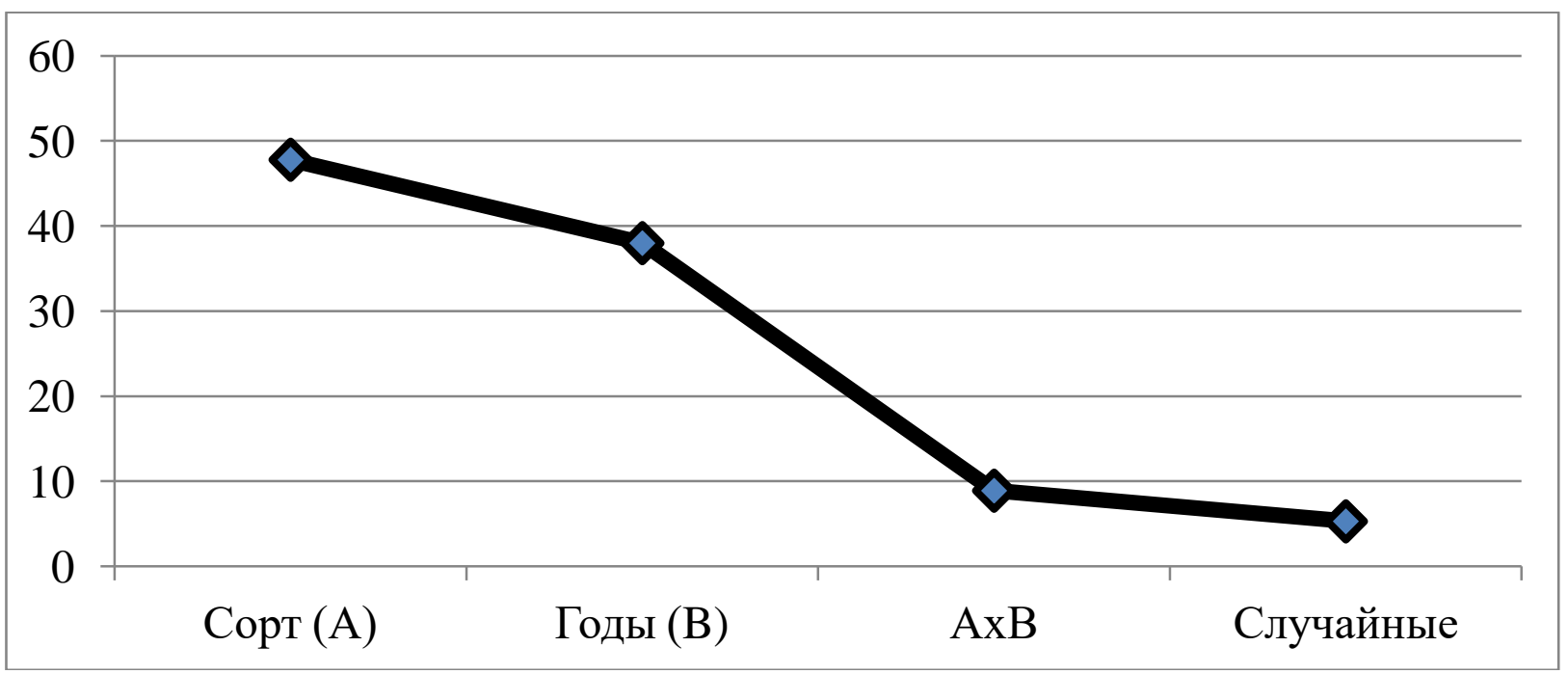

Доля влияния изучаемых факторов на изменчивость урожайности, \%

Взаимодействие «генотип - годы» показывает реакцию растения на любые изменения среды, и оно составляет 8,9\%. Знание доли влияния факторов «генотип», «годы» и их взаимодействия на урожайность необходимо для определения ареала распространения сортов и правильного выбора соответствующих технологий для возделывания.

Урожайность значительно варьировала по годам, от 149 (Новосибирская 15) до 307 г/м²
(Красноярская 12) в 2017 г., наибольшая амплитуда отмечена между образцами в 2018 г. - 161 (Новосибирская 14) - 444 г/м² (Свирель) и 206 (Новосибирская 14) - 439 г//2 (Предгорная) в 2019 г. По-разному реагировали образцы яровой пшеницы на изменение погодных условий во времени. Самую низкую урожайность за 3 года показал сорт Новосибирская 14, высокую Предгорная (табл.). 
Вестник КрасТАУ. 2020. № 1

Показатели экологической адаптивности образцов яровой пшеницы сибирской селекции (2017-2019 гг.)

\begin{tabular}{|c|c|c|c|c|c|c|}
\hline \multirow[t]{2}{*}{ Образец } & \multirow[t]{2}{*}{$\begin{array}{c}\text { Группа } \\
\text { спелости }\end{array}$} & \multicolumn{2}{|c|}{$\begin{array}{c}\text { Средняя } \\
\text { урожайность } \\
(\bar{x})\end{array}$} & \multirow[t]{2}{*}{$\begin{array}{c}\text { Показатель } \\
\text { стабильности } \\
\left(\mathrm{st}^{2}\right)\end{array}$} & \multicolumn{2}{|c|}{$\begin{array}{c}\text { Стабильная } \\
\text { урожайность } \\
\text { (А) }\end{array}$} \\
\hline & & $\Gamma / M^{2}$ & Место & & $\Gamma / \mathrm{M}^{2}$ & Место \\
\hline Алтайская 70, st. & 04 & 308,3 & 16 & 0,64 & 246,3 & 11 \\
\hline Новосибирская 15 & 03 & 192,8 & 32 & 0,53 & 140,0 & 30 \\
\hline Канская & 04 & 228,5 & 30 & 0,35 & 135,5 & 32 \\
\hline Чулымская & 04 & 209,2 & 31 & 0,80 & 187,2 & 20 \\
\hline Зоряна & 04 & 228,6 & 29 & 0,58 & 174,8 & 26 \\
\hline Новосибирская 14 & 04 & 179,0 & 33 & 0,58 & 135,8 & 31 \\
\hline Скала & 04 & 235,2 & 27 & 0,18 & 71,3 & 33 \\
\hline Тулунская 12 & 04 & 272,3 & 24 & 0,51 & 194,8 & 19 \\
\hline Новосибирская 29 & 04 & 282,3 & 23 & 0,61 & 221,0 & 15 \\
\hline Новосибирская 31 & 04 & 238,6 & 26 & 0,60 & 184,5 & 21 \\
\hline Памяти Вавенкова & 04 & 244,5 & 25 & 0,54 & 180,3 & 23 \\
\hline Руслада & 04 & 233,7 & 28 & 0,72 & 198,9 & 18 \\
\hline Уярочка & 04 & 292,5 & 21 & 0,84 & 267,8 & 7 \\
\hline Омская 32 & 04 & 301,1 & 18 & 0,56 & 225,6 & 12 \\
\hline Алтайская 75, st. & 05 & 297,3 & 19 & 0,37 & 180,2 & 24 \\
\hline Омская 33 & 05 & 308,4 & 15 & 0,21 & 140,2 & 29 \\
\hline Омская Краса & 05 & 340,7 & 9 & 0,38 & 210,9 & 17 \\
\hline Сибирский Альянс & 05 & 304,3 & 17 & 0,25 & 152,3 & 28 \\
\hline Новосибирская 18 & 05 & 335,9 & 10 & 0,28 & 179,2 & 25 \\
\hline Красноярская 12 & 05 & 354,2 & 3 & 0,84 & 324,4 & 1 \\
\hline Курагинская 2 & 05 & 325,0 & 14 & 0,48 & 224,3 & 13 \\
\hline Ветлужанка & 05 & 292,8 & 20 & 0,55 & 217,9 & 16 \\
\hline K-543-2 & 05 & 353,7 & 4 & 0,74 & 303,8 & 3 \\
\hline K-518-4 & 05 & 343,8 & 7 & 0,80 & 308,3 & 2 \\
\hline K-524-2 & 05 & 329,6 & 13 & 0,30 & 181,1 & 22 \\
\hline K-527-2 & 05 & 351,2 & 5 & 0,52 & 248,4 & 10 \\
\hline Сигма 2 & 05 & 283,2 & 22 & 0,61 & 221,2 & 14 \\
\hline Предгорная & 05 & 367,8 & 1 & 0,55 & 273,8 & 6 \\
\hline Свирель, st. & 06 & 345,8 & 6 & 0,24 & 169,7 & 27 \\
\hline K-626-1 & 06 & 366,2 & 2 & 0,61 & 286,0 & 4 \\
\hline K-592-5 & 06 & 342,8 & 8 & 0,57 & 259,2 & 9 \\
\hline K-613-2 & 06 & 333,1 & 11 & 0,72 & 282,4 & 5 \\
\hline$\Gamma-44$ & 06 & 333,0 & 12 & 0,61 & 261,1 & 8 \\
\hline $\mathrm{HCP}_{05}$ & & 27,9 & & 0,16 & 27,7 & \\
\hline
\end{tabular}

*03 - раннеспелье; 04 - среднеранние; 05 - среднеспелье; 06 - среднепоздние сорта.

Более низкие показатели по урожайности имели в основном раннеспелые и среднеранние образцы пшеницы: Новосибирская 14, Новосибирская 15, Новосибирская 31, Чулымская, Канская, Зоряна, Руслада, Скала, Памяти Вавенкова. Достоверно превышают указанные образцы по урожайности среднеранние сорта: Тулунская 12, Новосибирская 29, Уярочка, Омская 32. На- личие весенне-летней засухи в годы полевых опытов не позволило среднеранним сортам реализовать их генетический потенциал продуктивности.

У среднеспелой группы на уровне стандарта (Алтайская 75) имели урожайность сорта: Омская 33, Сибирский Альянс, Ветлужанка, Сигма 2, Курагинская 2. Остальные 8 образцов существен- 
но превышали стандартный сорт по урожайности.

Среднепоздние образцы пшеницы показали в изучаемые годы достоверно выше урожайность, чем среднеранние.

Определение величины относительной стабильности показывает экологическую стабильность урожайности. Чем больше этот показатель, тем выше экологическая стабильность сорта по данному признаку. Самые высокие данные по относительной стабильности явили образцы селекции Красноярского НИИСХ: Красноярская 12, Уярочка, К-518-4, Чулымская, К543-2, К-613-2 и Руслада (Кемеровская обл.).

Существенно ниже показатели стабильности были у образцов, урожайность которых сильно варьировала по годам и в значительной степени зависела от складывающихся погодных условий в период вегетации: Скала, Омская 33, Свирель, Сибирский Альянс, Новосибирская 18, К-524-2, Канская, Алтайская 75, Омская Краса. Остальные сорта имели промежуточный показатель стабильности.

Изучаемый материал представлен образцами, которые в различной степени сочетали среднюю урожайность и стабильность. Самую высокую стабильную урожайность показал сорт Красноярская 12. Он по средней арифметической урожайности в классовых интервалах ранжированного ряда занимал третье место, по экологической стабильности - первое. Образцы Предгорная и К-626-1, превышающие по средней урожайности сорт Красноярская 12, по стабильной урожайности оказались ниже его. Сорт Красноярская 12 обеспечивает более устойчивую урожайность в резко различающихся агроэкологических условиях возделывания.

Особый интерес для производства и как исходный материал для селекции на адаптивность представляют образцы, выделившиеся по стабильной урожайности: К-518-4, К-543-2, Уярочка, К-613-2, Г-44, Курагинская 2, Омская 32, Алтайская 70, Сигма 2.

К сортам интенсивного типа, отзывчивым на улучшение условий произрастания в благоприятные годы и снижающим урожайность в неблагоприятные, можно отнести: Свирель, К-524-2, Новосибирская 18, Омская Краса, Сибирский Альянс, Алтайская 75.

К образцам, отзывчивым на улучшение условий вегетации, имеющим стабильную урожайность в ранжированном ряду ниже по срав- нению со средней арифметической, относятся: К-626-1, К-592-5, Предгорная, К-527-2.

Выделились образцы, дающие более низкие и стабильные урожаи в годы исследований: Чулымская, Руслада, Новосибирская 31, Зоряна, Новосибирская 15, Новосибирская 14.

Заключение. Определение показателя относительной стабильности и средней стабильной урожайности позволило дифференцировать образцы яровой мягкой пшеницы по их реакции на условия возделывания. Изученные образцы рекомендуются как исходный материал для селекции разных типов сортов с высокой устойчивостью к неблагоприятным условиям вегетации, адаптированных на изменение уровня агротехники.

\section{Литература}

1. Вавилов Н.И. Селекция как наука. Т. 1 // Избранные произведения. - Л.: Наука, 1967. - C. 328-342.

2. Головоченко А.П. Особенности адаптивной селекции яровой мягкой пшеницы в лесостепной зоне Среднего Поволжья / Поволж. науч.-исслед. ин-т селекции и семеноводства им. П.Н. Константинова. - Кинель, 2001. $-380 \mathrm{c}$.

3. Жученко А.А. Роль адаптивной системы селекции в растениеводстве XXI века // Коммерческие сорта полевых культур Российской Федерации. - М.: ИКАР, 2003. С 10-15.

4. Евдокимов М.Г. Селекция яровой твердой пшеницы в Сибирском Прииртышье. Омск, 2006. - 219 с.

5. Караульный Д.В., Кукреш Л.В. Использование критериев адаптивности для оценки сортов озимых зерновых культур // Вестник БГСХА. - 2010. - № 1. - С. 62-67.

6. Корзун О.С., Бруйло А.С. Адаптивные особенности селекции и семеноводства сельскохозяйственных растений. - Гродно: Издво ГГАУ, 2011. - $140 \mathrm{c}$.

7. Никулин А.Ф., Кадиков Р.К., Исмагилов Р.Р. Отзывчивость сортов яровой мягкой пшеницы на изменения условий вегетации // Вестник БГАУ. - 2012. - № 4. - С. 8-11.

8. Рыбась И.А. Повышение адаптивности в селекции зерновых культур // Сельскохозяйственная биология. - 2016. - Т. 51, № 5. C 617-626. 
9. Никитина В.И., Количенко А.А. Оценка экологической стабильности сортов яровой мягкой пшеницы на сортоучастках Красноярского края // Вестник КрасГАУ. - 2019. № 3. - C. 58-64.

10. Драгавцев В.А., Макарова Г.А., Кочетов А.А. и др. Некоторые задачи агрофизического обеспечения селекционных технологий для генетического повышения продуктивности и урожая растений // Агрофизика. - 2011. № 1. - C. 14-22.

11. Жученко А.А. Адаптивное растениеводство (эколого-генетические основы): теория и практика. - М.: Агрорус, 2008. - Т. 1. - 814 с.

12. Методика государственного сортоиспытания сельскохозяйственных культур (общая часть). Вып. 1. - М.: Колос, 1985. - 269 с.

13. Методика государственного сортоиспытания сельскохозяйственных культур. Вып. 2. Зерновые, крупяные, зернобобовые, кукуруза и кормовые культуры / ред. А.И. Григорьева. - М.: Колос, 1989. - 194 с.

14. Методические указания по изучению мировой коллекции пшеницы / сост. М.И. Руденко, И.П. Шитова, В.А Корнейчук; под ред. В.Ф. Дорофреева. - 3-е изд., перераб. Л.: Изд-во ВИР, 1977. -28 с.

15. Соболев Н.А. Методика оценки экологической стабильности сортов и генотипов // Проблемы отбора и оценки селекционного материала. - Киев: Наук. думка, 1980. C. 100-106.

\section{Literatura}

1. Vavilov N.I. Selekciya kak nauka. T. 1 // Izbrannye proizvedeniya. - L.: Nauka, 1967. S. 328-342.

2. Golovochenko A.P. Osobennosti adaptivnoj selekcii yarovoj myagkoj pshenicy v lesostepnoj zone Srednego Povolzh'ya / Povolzh. nauch.issled. in-t selekcii i semenovodstva im. P.N. Konstantinova. - Kinel', 2001. - 380 s.

3. Zhuchenko A.A. Rol' adaptivnoj sistemy selekcii $\mathrm{v}$ rastenievodstve XXI veka // Kommercheskie sorta polevyh kul'tur Rossijskoj Federacii. - M.: IKAR, 2003. - S. 10-15.
4. Evdokimov M.G. Selekciya yarovoj tverdoj pshenicy v Sibirskom Priirtysh'e. - Omsk, 2006. - $219 \mathrm{~s}$.

5. Karaul'nyj D.V., Kukresh L.V. Ispol'zovanie kriteriev adaptivnosti dlya ocenki sortov ozimyh zernovyh kul'tur // Vestnik BGSKHA. 2010. - № 1. - S. 62-67.

6. Korzun O.S., Brujlo A.S. Adaptivnye osobennosti selekcii i semenovodstva sel'skohozyajstvennyh rastenij. - Grodno: Izd-vo GGAU, 2011. - $140 \mathrm{~s}$.

7. Nikulin A.F., Kadikov R.K., Ismagilov R.R. Otzyvchivost' sortov yarovoj myagkoj pshenicy na izmeneniya uslovij vegetacii // Vestnik BGAU. -2012. - № 4. - S. 8-11.

8. Rybas' I.A. Povyshenie adaptivnosti v selekcii zernovyh kul'tur // Sel'skohozyajstvennaya biologiya. - 2016. - T. 51, № 5. - S. 617-626.

9. Nikitina V.I., Kolichenko A.A. Ocenka ekologicheskoj stabil'nosti sortov yarovoj myagkoj pshenicy na sortouchastkah Krasnoyarskogo kraya // Vestnik KrasGAU. - 2019. - № 3. C. 58-64.

10. Dragavcev V.A., Makarova G.A., Kochetov A.A. i dr. Nekotorye zadachi agrofizicheskogo obespecheniya selekcionnyh tekhnologij dlya geneticheskogo povysheniya produktivnosti i urozhaya rastenij // Agrofizika. - 2011. - № 1. S. 14-22.

11. Zhuchenko A.A. Adaptivnoe rastenievodstvo (ekologo-geneticheskie osnovy): teoriya i praktika. - M.: Agrorus, 2008. - T. 1. - $814 \mathrm{~s}$.

12. Metodika gosudarstvennogo sortoispytaniya sel'skohozyajstvennyh kul'tur (obshchaya chast'). Vyp. 1. - M.: Kolos, 1985. - 269 s.

13. Metodika gosudarstvennogo sortoispytaniya sel'skohozyajstvennyh kul'tur. Vyp. 2. Zernovye, krupyanye, zernobobovye, kukuruza i kormovye kul'tury / red. A.I. Grigor'eva. M.: Kolos, 1989. - $194 \mathrm{~s}$.

14. Metodicheskie ukazaniya po izucheniyu mirovoj kollekcii pshenicy / sost. M.I. Rudenko, I.P. Shitova, V.A Kornejchuk; pod red. V.F. Dorofeeva. - 3-e izd., pererab. - L.: Izdvo VIR, 1977. - $28 \mathrm{~s}$.

15. Sobolev N.A. Metodika ocenki ekologicheskoj stabil'nosti sortov i genotipov // Problemy otbora i ocenki selekcionnogo materiala. Kiev: Nauk. dumka, 1980. - S. 100-106. 